\title{
Nurses' Experience towards Caring for Children with Proven Covid-19 Infection at Pediatric Intensive Care Unit
}

\author{
Mostafa Amr', Reham El - Saeed Hashad², Gehan El Nabawy Ahmed ${ }^{3}$, Omayma Mustafa \\ Abo Samra ${ }^{4}$ \\ ${ }^{1}$ Professor of Psychiatric Medicine, Faculty of Medicine, Mansoura University. Egypt \\ ${ }^{2,4}$ Lecturer of Pediatric Nursing, Faculty of Nursing, Mansoura University ,Egypt \\ ${ }^{3}$ Assistant professor of Pediatric Nursing, Faculty of Nursing, Mansoura University ,Egypt
}

\begin{abstract}
Background: The COVID-19 pandemic has been the talk of the world for several months in 2020, reflecting a new public health challenge that poses a significant threat to nurses' lives and well-being, resulting in a significant impact on their principles or experiences in the treatment of pediatric patients with covid-19. This study aimed to investigate nurses' experience towards caring for children with proven covid-19 infection at pediatric intensive care unit. Subject and Method: Design: A qualitative descriptive phenomenological study was conducted at Pediatric Intensive Care Units (PICU) affiliated to Mansoura University Children's Hospital (MUCH). Subject: It included 14 nurses who were caring for children who had covid-19 infection, either suspected or confirmed. Tools: Semi-structured interviews were conducted using the WhatsApp mobile messaging service to obtain data. The data was analyzed using Colaizzi's approach. Lincoln and Guba's criteria were used to determine the study's rigor. Results: Mental state, emotional state, and caring context were identified as three primary themes and six subthemes. Conclusion: Nurses working at pediatric intensive care unit caring for children with suspected or confirmed covid-19 infection reported a state of mental and emotional anguish, as well as working under insufficient professional circumstances. Recommendation: Increasing hospitals' attention on giving psychological support to nurses and training in coping skills, since COVID-19 outbreak has put enormous strain on hospitals, with frontline nurses being the most severely affected.
\end{abstract}

Keywords: Covid-19 infection, Nurses' experience, Pediatric Intensive Care Units. 


\section{Introduction:}

COVID-19 (novel corona virus illness) is a respiratory viral disease that has spread fast over the world. Because of its rapid spread, high mortality, and lack of a cure or vaccine, it is considered an international pandemic. Because of the virus's rapid dissemination, nurses in Emergency and Intensive Care Units are likely to come across pediatric patients who have COVID-19 ${ }^{(1)}$.

Acute respiratory distress syndrome (ARDS) is a severe form of acute respiratory distress COVID-19 caused by corona virus 2 (SARSCoV- 2), a positivesense RNA virus (A virus in which the genetic material is RNA). Corona viruses are a prevalent cause of minor respiratory infections in both infants and adults. Several novel corona virus strains or mutations have emerged in recent decades, including severe acute respiratory syndrome (SARS) in 2003 and Middle Eastern respiratory syndrome in $2012^{(2)}$. These new strains are frequently linked to high levels of mortality and pathogenicity. These earlier strains did not have the same international spread as COVID-19, and as a result, they did not create as much have or achieve pandemic status ${ }^{(3)}$.

Patients with symptoms of COVID-19related severe illness are referred to a hospital for treatment. COVID-19' patients are treated in designated corona virus units, which provide specialized care and infrastructure. During epidemics, these acute care units are frequently isolated. Isolation due to COVID-19 hospitalization might last up to two weeks ${ }^{(4)}$. For both patients and healthcare personnel, prolonged isolation is a barrier to genuine care. Nurses are currently in the forefront of caring for COVID-19 patients. Nurses with unique expertise are needed to care for patients in such a medical emergency. In a nutshell, patient care is a complicated procedure $^{(5)}$.

Nurses perform services and have an impact on patient satisfaction by providing ethical care guided by human contact. Patients' treatment and care have been hampered by a lack of data on the threat of severe disease and a scarcity of specific pharmacological and interventional treatments; all treatments are symptomatic and performed on the basis of knowledge ${ }^{(6)}$. COIVD-19 patients also require special care specifically, supportive care; this demands the availability of adequate equipment and infrastructure, as well as knowledge, attitude, and ability of experienced nurses. Medical facilities and employees are in short supply, treatment' system confusion, the unpredictability of the illness, societal separation, and the virus's widespread distribution all had 
serious effects for healthcare systems in more than 200 nations around the world. In this crisis, providing high-quality nursing care to COVID-19 patients is a big issue ${ }^{(7)}$. While taking care of COVID-19-positive children in the PICU, nurses are exposed to tremendous dangers, including death. Working-related stress, the influx of people into hospitals on a regular basis, inadequate capacity of a hospital, and a low nurse-to-patient ratio have all contributed to the problem of unsatisfactory treatment. Accordingly, it's vital to consider the nurses' previous care' experiences (8). Care is a complex connection between the patients and the nurse that may be studied in a variety of ways. Qualitative' researches can help nurses better understand lives, procedures, processes, and events as they occur in a natural setting without intercession. Phenomenological technique can give specific details about humans 'communications and the lived experience of nurses, who care the critically ill children with COVID-19, and it can be used to investigate the significance and problems of these encounters ${ }^{(9)}$.

The study's fundamental guiding philosophy was Husserl's descriptive phenomenology which is concerned with the participants' actual experiences. In this rising pandemic and healthcare catastrophe, no qualitative research has studied nurses' experiences taking care of COVID-19-infected children ${ }^{(\mathbf{1 0})}$.

\section{Aim of the study}

This research was carried out to explore nurses' experience towards caring for children with proven covid-19 infection at pediatric intensive care unit.

\section{Design:}

A descriptive qualitative' phenomenology study was utilized on the way to understand as well as investigate pediatric intensive care unit nurses' views and experiences with children with suspected or confirmed covid-19 infection. Bracketing, intuiting, analyzing, and interpreting were the four steps of Husserl's descriptive phenomenology ${ }^{(10)}$.

\section{Setting:}

This study was conducted at the Pediatric Intensive Care Units (PICU) affiliated to Mansoura University Children's Hospital (MUCH) in Egypt from 29 July-30 August 2020.

\section{Subjects:}

The study included a purposeful sample of 14 nurses working at the above-mentioned study setting who met the inclusion criteria, which included participants with a wealth of knowledge about the phenomenon and nurses with experience of caring for hospitalized children who have been diagnosed with COVID-19 as well as 
sufficient availability for the interview. Reluctance of engaging in the trial and nurses who have been diagnosed with COVID-19 were among the study's exclusion criteria. In addition, the participants' informed consent was sought before to the interview.

\section{Tool for data collection:}

The author created a semi-structured interview questionnaire in Arabic language after examining the literature ${ }^{(\mathbf{1 1}, \mathbf{1 2})}$ on the subject. It consists of 30 open-ended questions that the authors gathered from nurses during an interview to collect data about their experiences with experience of caring for hospitalized children who have been diagnosed with COVID-19. It was divided into two sections as follows:

Part (1): Concerned about nurses' characteristics such as age, sex, years of experience in the PICU, and shift work.

Part (2): Concerned about nurse's concepts and experience towards caring of pediatric patient with proven COVID -19 which included the following.

- The high mental demands faced by nurses in the COVID-19 PICU

- Anxiety, stress, and their consequences on pediatric patient care as well as nurse mental health
- Fear and worrying degree among nurses during the current corona virus crisis.

- Emotional participation in the care of critically affected pediatric corona virus patients.

- Nurses' concerns about the suffering and hardships of pediatric patients suffering from COVID-19's severe health effects.

- unconstructive emotional as well as professional effects for nurses as a result of a huge numeral of daily deaths caused by COVID-19

- Requirement of assistance and equipment during care of covid-19 patients by nurses.

\section{Methods:}

- After clarifying the study's goal, an official permission was obtained by submitting an official letter to the director of the hospital and the head of the pediatric critical care unit of the indicated setting to perform the study. After analyzing the relevant literature, the researcher created the tools.

- The tool was developed after a review of the relevant literature and was subjected to content validity testing by a jury of three pediatric nursing experts and two qualitative research specialists for clarity, relevancy, applicability, comprehensiveness, understanding, and 
ease of implementation. Minor changes were made based on their feedback.

- This study's data was collected over the course of one month, from July 29 to August 30, 2020. To determine the feasibility, application, and clarity of the tool, a pilot research was conducted on two nurses who provide care for children with or suspected of having covid-19 at the indicated setting (10\% of the total sample size). And nurses who participated in the pilot study were excluded from the final study sample as minor modifications were applied according to the opinions of qualitative research specialists, as each participant's comment was coded during the analysis process to improve dependability and ease for its analysis.

- The interviewer had prior qualitative interviewing and research experiences therefore the researcher initiates to ask questions and listens carefully to the responses of the participants and the researcher videotaped the interviews with the consent of the participants, which were then re-examined and discussed with two more specialists. Each interview lasted between 30 and 75 minutes, and if necessary, two sessions were held. Due to limitations at the time in the COVID-19 unit, such as complete isolation, with no one permitted to enter or leave the section, high risk of viral transmission to other individuals, and Nurses' workload that is really tough. The interviews were conducted using Whats App mobile software (video calling, voice, and text messages).

\section{Ethical Considerations:}

In 2020, the research ethics committee of the Faculty of Nursing at Mansoura University granted ethical permission. After explaining the purpose of the study and reassuring all nurses that their personal information would be kept private and that only the survey' results will be made anonymously published, and nurses had the right to withdraw from the study at any time, oral consent was obtained from each nurse for their participation in this study.

\section{Data Analysis:}

The data was analyzed using the descriptive Colaizzi approach. The following are the seven steps in this method: (1) Organizing descriptions, (2) Understanding the meanings of words on a deeper level, (3) Getting the most important sentences out, (4) Developing a conceptual framework for the major issues, (5) Organizing the ideas and subjects into categories, (6) Creating detailed issues' descriptions that are examined, and (7) 
making the data' validation according to Linco's and Guba's four criteria (Table 2).

Therefore, the study's rigor was determined using Lincoln and Guba's four criteria: credibility, conformability, transferability and reliability ${ }^{(\mathbf{1 3})}$.The trustworthiness of the researchers was created through their continued involvement with data, result, detection of divergent results, and member' checks.14 nurses with valuable expertise taking care of COVID-19 young children and suspected were enlisted for providing a large and extensive data set for conformability. The researchers also looked into and explained every study' aspect, from data collection to sampling as well as processing, and then they were compared the results. Two qualitative' research experts double-checked that descriptions and coding. The researchers utilized more than two questions to analyze the phenomena in order to corroborate the findings. To boost dependability, coding methods were applied during the analytical process.

\section{Results}

Concerning characteristics of the studied nurses, Table (3) revealed that, fourteen nurses caring for children with proven covid-19 infection participated in this study. $71.4 \%$ were women and $28.6 \%$ men. The participants' mean age of was 28.31 years $(\mathrm{SD}=3.42)$ with their mean work experience was 7.21 years $(\mathrm{SD}=2.53)$. In general, the majority of nurses offered ongoing care. Furthermore, $64.3 \%$ worked the morning' shifts, $28.6 \%$ worked the evening' shifts, and $7.14 \%$ worked the night' shifts. $7.14 \%$ of all participants had a month of work experience in the COVID19 isolation' unit, while, $78.6 \%$ had two months and the remaining, $14.3 \%$ had three months of work' experience.

Table (4) clarified that three main themes and six subthemes were identified in relation to the experience of nurses caring for pediatric COVID-19 patients using descriptive phenomenology: mental status (subthemes included "anxiety and stress" and "fear"), emotional' condition (subthemes incorporated "suffering and affliction" and "waiting for death"), and care context (subthemes included "turmoil" and "lack of support and equipment").

\section{Mental Condition}

Nurses caring with PICU children with suspected or confirmed covid-19 may have severe mental demands, which may impair the quality of care they can give. Anxiety, worry, and fear, according to nurses, all have a substantial impact on the care of COVID-19 patients (Table 4).

\section{Stress and Anxiety}

Stress and anxiety had a severe impact on both patient' care and nurse mental health. 
These nurses' accounts show that their mental health is essential for their patient' care, as well as they is fully aware of illnesses' implications on the care amid the present coronavirus outbreak. Nurses cited a variety of reasons for their concern, including a stressful workplace, doubts, the issue's ramifications, and tension due to the emergence of an unfavorable event. When nurses remarked things like, "How anxious I am, there is no moment when I am not anxious, my whole body is shaking...," it was evident that anxiety and stress are key elements in which nurses are dealing throughout the present corona virus pandemic. (A13) My whole body sweats as I come close to the sufferer, making it impossible for me to operate effectively (A2). What good is it for the world to be so involved and then accomplish nothing?

\section{(A3) (Table 4).}

\section{Fear or terror}

Usually, anxiety and terror may be distinguished. Fear causes nurses in the COVID-19 pediatric patient care' scenario to be more concerned, particularly when it comes to becoming sick and spreading the disease to others. It can be seen in their expressions, for example: perhaps I'm unwell too; I might infect others if I'm a carrier.; my symptoms imply that I am ill as well; I'm always worried that I'll get sick as well.; I'll easily catch the disease; I'm not going to be able to stay here much longer; I wish it would come to an end sooner; I'm frightened I'll make a mistake that may harm the patients.; I'm afraid $(\mathrm{A} 1,6)$. We're all dying these days, how dreadful it is. (A7) (Table 4).

Emotional ConditionLong shifts and quarantine circumstances at the hospital, including the absence of visits and the separation from relatives, were discussed by the nurses. COVID-19-induced discomfort and misery in individuals with significant health conditions, as well as the feeling of being on the verge of dying, affected nurses emotionally. According to the nurses, emotional participation in the treatment of those harshly damaged patients might have a substantial effect on health' care (Table 4).

\section{Affliction and Suffering}

Nurses expressed concern for patients who are distress from the serious health implications of COVID-19. The interviewees described how seclusion and quarantine measures impacted family' dynamics and even work' performance. Nurses clarified that, the difficulties and emotional involvement with patients in the COVID-19 PICU have challenged their application of actual nursing care' principles as illustrated in (Table 4) such as, "I just want to put an end to these trying days," "No one can live with these 
challenges," "I hope God would intervene sooner to help end this tragedy," "Do you believe I can think about the principles of caring now?" Don't mention that; we are unable to see or see our families, and it is awful. (A10). I can't see my family because We've all gathered in the ward; It's excruciatingly difficult to be separated from them; Everything is weighing heavily on my shoulders; it is quite difficult; Now I'm considering returning to consider my care theory; In this disaster, no one can think about these things $(\mathrm{A} 5,9,11)$. I'm not sure what my kids are up to right now" (A8).I pity the patients; some of them are fairly young, and their deaths pain me; a man dies of simple shortness of breath, and they have dreams about their impoverished family (A12)

\section{Waiting for Death}

Nurses have had unpleasant emotional and professional implications as a result of a huge number of daily deaths following COVID-19. In addition to all of the problems and sufferings brought on by the increased strain in the COVID-19 care PICU, the fear of dying among nurses has turned into a problem, distracting them from giving actual patient care:

Nurses have withdrawn from patient care because they are worried with the prospect of losing a life or anticipating death. A few of individuals expressed concerns about impending death, which they extended to the patients, themselves, families, as well as coworkers, detracting greatly from their concentration on care, as seen in (Table 4): so who cares? This is too much work; the mortality rate is rising; I wish no one was sad; many of our coworkers have died; it's difficult to grasp the number of deaths; and cemeteries are running out of space (A5, A14). I sometimes have the impression that I can't go too close to the patient because I don't want to die, and death is the end of this situation (A12)

\section{Care Contexts}

The nurses' remarks about the care context revealed turbulence and a lack of support and equipment. To offer correct care for COVID-19 patients, the care context encompasses a variety of components such as supportive equipment, personal protective equipment, and facilities, as well as appropriate regulations as well as environmental circumstances. The health care center's contextual flaws, according to nurses, are a substantial obstacle to giving quality care.

\section{Turmoil}

Concerning the nurses' portrayal of the PICU's questionable management and policies of care for COVID-19 patients, the disruption in care, as well as staffing constraints and COVID-19 unit' limitations that impacted nurse intervention, were 
highlighted by participants (Table 4).They clarified that we are unable to face a huge patients' number because the nurses' numbers is limited, and each patient requires the same amount of effort as a few typical patients (A10). I honestly have no idea how to look after them anymore; whatever I do, it's as if I'm not doing anything at all (A6). When our numbers are so little, and there is so much strain on coworkers, you identify how many people come per day, and it's just hospitalization after hospitalization (A2). It would be much better if there was a clear policy on this disease on which we could act; our treatment is based on our prior experiences. They instructed me to come work here and I didn't know what I was doing, therefore I believe a sequence of obvious and scientific intervention as well as management regulations should be supplied (A7)

\section{A Lack of Equipment and Support}

According to nurses, the most basic medical services are insufficient for the management of COVID-19 patients. Nurses emphasized the significance of proactive preparedness in the event of an urgent or emergent healthcare emergency, emphasizing the significance of precise policies in addition to appropriately qualified employees as well as the acquisition of the required equipment for care of patients as their key priorities in the environment of intervention.(Table 4) shows that: "We don't have enough facilities; there are few basic facilities, therefore we don't have a well-known employment scenario, but we must work." This isn't a typical isolated ward (A3) other people's collaboration isn't particularly good (A4).No one is held responsible (A8). I am confident that if we become infected with Covid-19, our work environment will not allow us to be isolated and treated (A13). 
Table 1: An example of a set of interview questions

1- Tell us about your experience of caring for COVID-19 patients first and foremost. What is
your educational background?
2- Make clear to us your day-to-day experience of intervening COVID-19 infected individuals
3-Inform us about your worrying degree in caring for children with proven covid-19 infection at
pediatric intensive care unit.
4- Describe the emotional and professional consequences of a huge number of daily deaths as a
result of COVID-19.


Table 2: Data Analysis Stages Using the Colaizzi Descriptive Method

\begin{tabular}{|c|c|}
\hline A brief description (Action) & Stage \\
\hline $\begin{array}{l}\text { Using WhatsApp for video calls, voice calls, and texts, as well as } \\
\text { footage the interviews }\end{array}$ & Organizing descriptions \\
\hline $\begin{array}{l}\text { Transcribing, rereading the text to gain a fundamental and in- } \\
\text { depth understanding of the participants' statements }\end{array}$ & Understanding the meanings of words on a deeper level \\
\hline Examining the nurses' explanations and highlighting the key lines & Getting the most important sentences out \\
\hline $\begin{array}{l}\text { Taking the most significant explanations and putting them into } \\
\text { context by particular concepts (explaining the significance of the } \\
\text { key components) }\end{array}$ & Developing a conceptual framework for the major issues \\
\hline $\begin{array}{l}\text { The concepts that were discovered were categorized (based on } \\
\text { conceptual resemblance). }\end{array}$ & Organizing the ideas and subjects into categories \\
\hline $\begin{array}{l}\text { The phenomenon' description beneath investigation is expressed in } \\
\text { a clear and straightforward manner. }\end{array}$ & Creating detailed issues' descriptions \\
\hline $\begin{array}{l}\text { Lincoln and Guba's criteria were applied (credibility, } \\
\text { transferability, reliability, and verification) }\end{array}$ & making the data' validation \\
\hline
\end{tabular}


Table 3: Participants' Nurse's Characteristics

\begin{tabular}{|c|c|c|c|c|c|c|c|c|c|c|c|c|c|}
\hline ID & Age & \multicolumn{2}{|c|}{ Sex } & \multicolumn{3}{|c|}{ Position } & \multicolumn{3}{|c|}{ Shift 'Work } & $\begin{array}{c}\text { Work' } \\
\text { Experience }\end{array}$ & \multicolumn{3}{|c|}{ Time to Attend Coronavirus } \\
\hline A1 & $24 y$ & \multicolumn{2}{|c|}{ Female } & \multicolumn{3}{|c|}{ Nurse } & \multicolumn{3}{|c|}{ Evening } & $4 y$ & \multicolumn{3}{|c|}{ Two months } \\
\hline A2 & $25 y$ & \multicolumn{2}{|c|}{ Female } & \multicolumn{3}{|c|}{ Nurse } & \multicolumn{3}{|c|}{ Morning } & $6 y$ & \multicolumn{3}{|c|}{ Two months } \\
\hline A3 & $27 y$ & \multicolumn{2}{|c|}{ Male } & \multicolumn{3}{|c|}{ Supervisor } & \multicolumn{3}{|c|}{ Night } & $6 y$ & \multicolumn{3}{|c|}{ Two months } \\
\hline A4 & $29 y$ & \multicolumn{2}{|c|}{ female } & \multicolumn{3}{|c|}{ Nurse } & \multicolumn{3}{|c|}{ Morning } & $9 y$ & \multicolumn{3}{|c|}{ Three months } \\
\hline A5 & $28 y$ & \multicolumn{2}{|c|}{ female } & \multicolumn{3}{|c|}{ Nurse } & \multicolumn{3}{|c|}{ Morning } & $7 y$ & \multicolumn{3}{|c|}{ Two months } \\
\hline A6 & $28 y$ & \multicolumn{2}{|c|}{ male } & \multicolumn{3}{|c|}{ Nurse } & \multicolumn{3}{|c|}{ Morning } & $8 y$ & \multicolumn{3}{|c|}{ Two months } \\
\hline A7 & $30 y$ & \multicolumn{2}{|c|}{ female } & \multicolumn{3}{|c|}{ Head nurse } & \multicolumn{3}{|c|}{ Morning } & $12 y$ & \multicolumn{3}{|c|}{ One month } \\
\hline A8 & $28 y$ & \multicolumn{2}{|c|}{ female } & & Nur & & & Morning & & $8 y$ & & $\mathrm{o} \quad \mathrm{mo}$ & \\
\hline A9 & $30 y$ & & & & Head & & & Evening & & $11 \mathrm{y}$ & & ree mor & \\
\hline A10 & $31 y$ & & & & Nur & & & Morning & & $7 y$ & & $\mathrm{o} \quad \mathrm{mo}$ & \\
\hline A11 & $29 y$ & & & & Nur & & & Evening & & $7 y$ & & $\mathrm{o} \quad \mathrm{mo}$ & \\
\hline A12 & $32 y$ & & & & Super & & & Morning & & $5 y$ & & $\mathrm{o} \quad \mathrm{mo}$ & \\
\hline 13 & $31 \mathrm{y}$ & & & & Nur & & & Morning & & $7 y$ & & $\mathrm{o} \quad \mathrm{mo}$ & \\
\hline A14 & $35 y$ & & & & Head & & & Evening & & $14 y$ & & $\mathrm{mo}$ & \\
\hline $\mathrm{M} \pm \mathrm{SD}$ & $\mathbf{M} \pm \mathbf{S D}$ & $\mathbf{F}$ & $\mathbf{M}$ & Nurse & $\mathbf{H N}$ & Supervisors & $\mathrm{M}$ & $\mathrm{E}$ & $\mathrm{N}$ & $\mathrm{M} \pm \mathrm{SD}$ & One & two & three \\
\hline & & $71.4 \%$ & $28.6 \%$ & $64.3 \%$ & $21.4 \%$ & $14.3 \%$ & $64.3 \%$ & $28.6 \%$ & $7.1 \%$ & & $7.14 \%$ & $78.6 \%$ & $14.3 \%$ \\
\hline Total & & & & & & & U nur: & & & & & & \\
\hline
\end{tabular}


Table 4: During the data analysis, themes and subthemes emerged as illustrated.

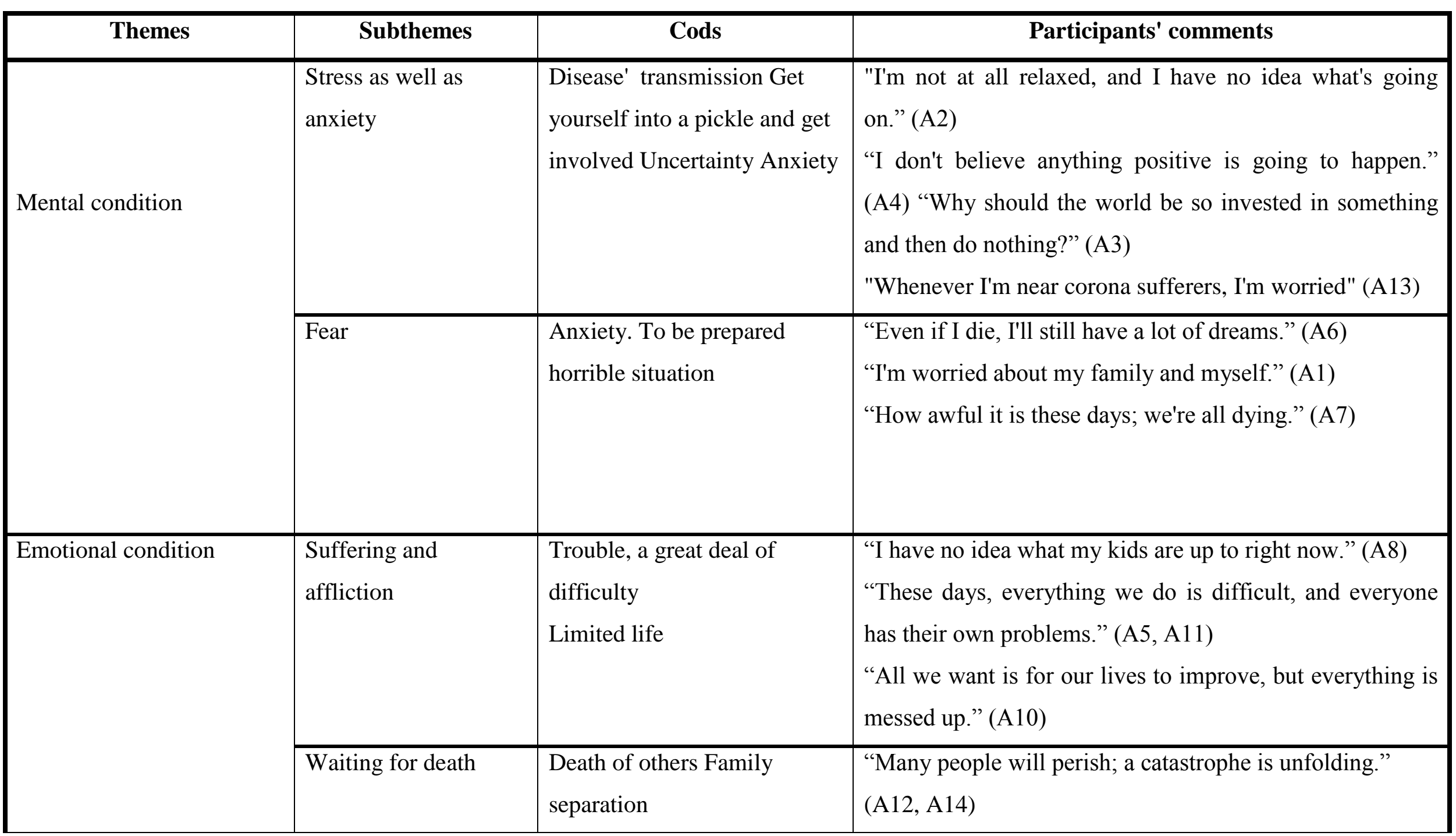




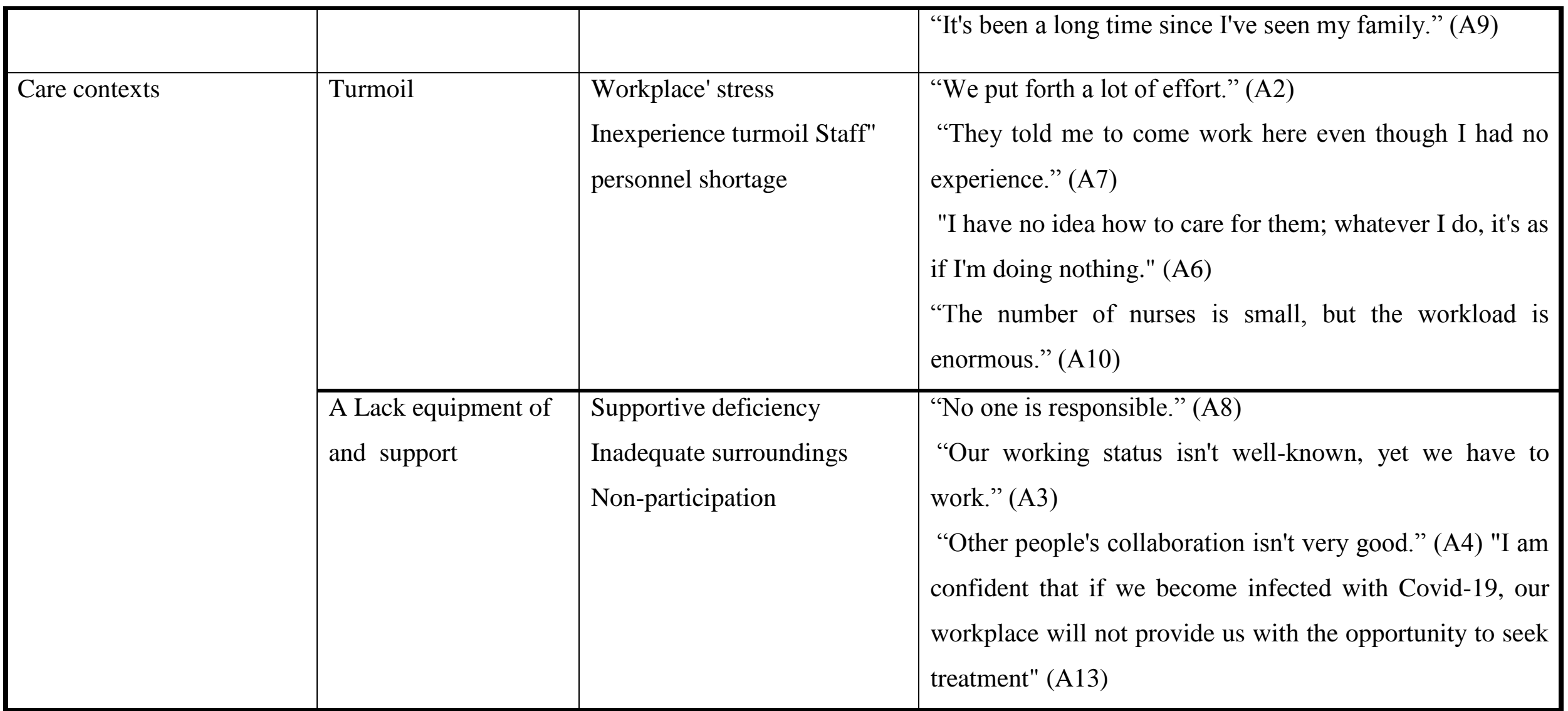




\section{Discussion}

The fight against the corona-virus disease (Covid-19) is becoming more visible and important every day. The COVID-19 outbreak has put a lot of strain on hospitals, and nurses on the front lines are especially hard hit. Nurses need additional help when it comes to COVID-19 care. Policymakers and nursing management, according to the nurses, must assess the need for nursing intervention in the present corona virus' crisis, make a strategy ahead of time, and provide nurses with the necessary training to deal with the unexpected and extraordinary needs of care for COVID-19-infected children. Furthermore, Hospitals should focus on providing nurses with psychological assistance and coping methods to help them cope with the stress and anxiety that comes with caring for infected patients with the Corona virus ${ }^{(\mathbf{1 4 , 1 5})}$.

There is a scarcity of qualitative researches on the COVID-19 era's patient care experience. The experience of pediatric intensive care unit nurses in caring for children with confirmed covid-19 infection was investigated in this study. Mental health, emotional health, and care setting were the main themes that emerged from the nurses' statements. The nurses' most important concerns were anxiety, stress, terror, witnessing the deaths of patients and coworkers, as well as poor treatment conditions and a lack of resources ${ }^{(8)}$.

In terms of the gender of the nurses who took part in the study, less than threequarters of the nurses were female (Table 3). This conclusion was consistent with Zohreh Karimil et al., (2021) ${ }^{(16)}$, who reported that 66.66 percent of participants in their study of Nurses' Lived Experience, who Caring for COVID-19 patients in Iran were female. These findings, according to the researcher, could be related to the fact that girls are admitted to nursing school at a higher rate than boys. The current study's findings revealed that feelings of worry, tension, and dread defined the first theme of nurses' remarks regarding mental health, and that the nurses' concerns and fears were commonly linked to the care context surrounding COVID-19 table (4).This finding matched that of Zohreh Karimi1 et al., ( 2021) ${ }^{(16)}$, who investigated Nurses' Lived Experience, who Caring for COVID-19 patients in Iran and found that, an uncomfortable surroundings, doubts, the scenario's repercussions, and tension for the emergence of a terrible circumstance were all identified as reasons for their uneasiness. The nurses' claims about their mental health in this study could be related to exceptionally high job challenges, as well as the widespread prevalence of covid-19 and its devastating repercussions. 
The second theme of nurses' statements represents their depiction of being emotionally exaggerated by the agony and PICU pediatric patients' affliction among serious health problems caused by COVID-19, as well as the feeling of being on the verge of dying, as shown in the current study table (4). This finding was in an accordance with Park et al. (2020) ${ }^{(17)}$ and Herandez-Platero et al. (2021) (18), who conducted a study about "Effect of isolation practice on the transmission of middle east respiratory syndrome coronavirus among hemodialysis patients" and discovered that the participants' feelings of being constrained by seclusion and quarantine practices had an impact on their family processes as well as their work performance. This finding could be attributed to the fact that, the large number of daily deaths following COVID-19 has had negative emotional and professional consequences for nurses According to this assessment.

Nurses described confusing treatments and intervention' rules in place for pediatric COVID-19 patients, as well as care interruptions and shortages of personnel and limits on the COVID-19' units, which hindered nursing intervention table (4): This result was disagree with Schwartz (2020) ${ }^{(19)}$ and Lulgjuraj (2021) ${ }^{(20)}$, who conducted a study about "Protecting health care workers during the COVID-19 coronavirus outbreak-lessons from Taiwan's SARS response" and stated The nurses reported having enough medical protective equipment and developing a wide range of measures to prevent the spread of infectious diseases, but that they require greater psychological support from their workplace. This result could be related to system inefficiencies and a large number of pediatric patients in critical condition, according to the researchers. A notable limitation of this study was that the researchers were denied entrance to the hospital due to the COVID-19 units' poor condition; an alternative method for conducting interviews was to use the mobile messaging network and WhatsApp, which partially addressed this barrier.

\section{Conclusion}

Nurses working at pediatric intensive care unit caring for children with suspected or confirmed covid-19 infection reported a state of mental and emotional anguish, as well as working under insufficient professional circumstances.

\section{Recommendation}

The study recommended that:

- Increasing hospital' attention on giving psychological support and training in coping skills for nurses to adapt to the sudden and extreme demands of caring for pediatric 
patients, as the COVID-19 outbreak has put enormous strain on hospitals, with frontline nurses being the most severely affected.

- It is important for health care systems and nurse leaders to understand the emotional and physical experiences of pediatric nurses, to support and protect their nurses, and to recognize these needs and experiences as they prepare for future public health emergencies, especially when a transition of role is warranted.

\section{Limitations of the study}

A qualitative study should be conducted through relatively long face to face interviews in order to obtain a stronger rigor of data, but in this study, the data was collected in a short time. Besides, because of the urgent situation and to reduce the risk of infection for both the interviewee and interviewer, the data was collected via phone interviews.

\section{References}

1. Rothan HA. \& Byrareddy SN. The epidemiology and pathogenesis of coronavirus disease (COVID-19) outbreak. J Autoimmun.2020 ; 26:102433.

2. Yang J. Zheng Y. Gou X. Chen Z, Guo Q, Ji R, Wang H, Wang Y, Zhou Y. . Prevalence of comorbidities in the novel Wuhan coronavirus (COVID-19) infection: a systematic review and meta-analysis. Int $\mathbf{J}$ Infect Dis.2020;94:91-95. http://dx.doi.org/10.1016/j.ijid.2020.03. 017

3. Le HT. Nguyen DN. \& Beydoun AS. Demand for Health Information on COVID-19 among Vietnamese. Int J Environ ResPublic Health.2020; 17:E4377. PMID: 32570819

4. Lee PI. \& Hsueh PR. (2020). Emerging threats from zoonotic coronavirusesfrom SARS and MERS to 2019-nCoV. J Microbiol Immunol Infect; 43:3001130016. pii: S1684-1182.

5. Atieh QAT. Abdelrahman G. Ngoc ML. Ali ATM. Akash S. Thanh HV. Lam VN. Mohamed TG. Rashidul HM . et al . Awareness and Preparedness of Hospital Staff against Novel Coronavirus (COVID-2019): A Global Survey-Study Protocol.2020. SSRNdoi:10.2139/ssrn.35502949

6. Schoenhofer SO. van Wynsberghe A. \& Boykin, A.(. Engaging robots as nursing partners in caring: nursing as caring meets care-centered valuesensitive design. Int J Hum Caring.2019; 23(2):157-167. doi:10.20467/1091-5710.23.2.15714

7. Huh S.How to train health personnel to protect themselves from SARS-CoV-2 
(novel coronavirus) infection when caring for a patient or suspected case. $\mathrm{J}$ Educ Eval Health.2020 Prof.;doi:10.3352/ jeehp.2020.17.10

8. Qiu H. Tong Z. Ma P. Hu M. Peng Z. Wu W. Du B. \& China Critical Care Clinical Trials Group (CCCCTG). Intensive Care during the Coronavirus Epidemic. Intensive Care Med.2020; 46(4):576-578. doi: 10.1007/s00134-020-05966-y. Epub $2020 \mathrm{Feb} 20$.

9. Steinbock, AJ. The society of phenomenology and existential philosophy. In: The Reception of Husserlian Phenomenology in North America. Springer; 2019:267-281.22

10. Husserl E..The Phenomenology of Internal Time-Consciousness. Published by Indiana University Press;2020; 189.

11. Shekerdemian LS. Mahmood NR. Wolfe KK. Riggs BJ. Ross CE. McKiernan et al. . Characteristics and Outcomes of Children with Coronavirus Disease 2019 (COVID19) Infection Admitted to US and Canadian Pediatric Intensive Care Units. JAMA Pediatr.2020; 174(9):868-873. doi:10.1001/jamapediatrics.2020.1948

12. Galehdar N. Kamran A. Toulabi T. \& Heydari H. Exploring nurses' experiences of psychological distress during care of patients with COVID19: a qualitative study. BMC Psychiatry.2020; 20:489. https://doi.org/10.1186/s12888-02002898-1

13. Lincoln YS. \& Guba EG. Naturalistic Inquiry. Beverly Hills, Calif.: Sage Publications, C1985. ISBN: 08039243139780803924314.416 pages

14. Xie J. Tong Z. Guan X. Du B. Qiu H. \& Slutsky AS.Critical care crisis and some recommendations during the COVID-19 epidemic in China. Intensive Care Med. 2020; 46(5):837840.27

15. Rimensberger PC. Kneyber MC. Deep A. Bansal M. Hoskote A. Javou hey E. et al. (2021). Caring for Critically Ill Children with Suspected or Proven Coronavirus Disease 2019 Infection: Recommendations by the Scientific Sections' Collaborative of the European Society of Pediatric and Neonatal Intensive Care. Pediatric Critical Care Medicine; 22(1):56-67.

16. Zohreh K. \& Zhila F. The Lived Experience of Nurses Caring for Patients with COVID-19 in Iran: A Phenomenological Study Risk Management and Healthcare Policy downloaded from 
https://www.dovepress.com/ by 41.33.88.70 on 20-Jan-2021.

17. HC. Lee SH. Kim J. Kim DH. Cho A. Jeon HJ. et al. Effect of isolation practice on the transmission of Middle East respiratory syndrome coronavirus among hemodialysis patients: a 2-year prospective cohort study. Medicine. 2020; 99(3):e18782. doi:10.1097/MD.00000000000187821

18. Hernández-Platero L. Solé-Ribalta A. Pons-Odena M. Cambra FJ. Jordan I. A pediatric intensive care unit's experience in managing adult patients with COVID-19 disease.2021. https://doi.org/10.1016/j.anpedi.2021.0 1.012

19. Schwartz J, King CC\& Yen MY. Protecting health care workers during the COVID-19 coronavirus outbreaklessons from Taiwan's SARS response. Clin Infect Dis. 2020 ; 71(15):858-860. doi: 10.1093/cid/ciaa255.

20. Lulgjuraj D. Hubner T. Radzinski N. \& Hopkins U. Everyone is Someone's Child: The Experiences of Pediatric Nurses Caring for Adult COVID-19 Patients Journal of Pediatric Nursing.2021; 60: 198-206. https://doi.org/10.1016/j.pedn.2021.06. 015. 